\title{
Distribution and interactions of pentachlorophenol in soils: The roles of soil iron oxides and organic matteris
}

\author{
Paul N. Diagboya ${ }^{\mathrm{a}, *}$, Bamidele I. Olu-Owolabi ${ }^{\mathrm{b}}$, Kayode O. Adebowale ${ }^{\mathrm{b}}$ \\ a Department of Physical Sciences, Landmark University, Kwara State, Nigeria \\ b Department of Chemistry, University of Ibadan, Ibadan, Nigeria
}

\section{A R T I C L E I N F O}

\section{Article history:}

Received 19 December 2015

Received in revised form 15 April 2016

Accepted 17 April 2016

Available online 22 April 2016

\section{Keywords:}

Sub-Saharan soils

Soil iron oxides removal

Soil organic matter removal

Sorption

Anionic pesticide

\begin{abstract}
A B S T R A C T
Soil iron oxides (IOs) and organic matter (OM) play varying roles in pentachlorophenol (PCP) retention and mobility, but the extent and mechanism are still unknown. Therefore, in order to have a better understanding of the adsorption of PCP on soils, batch sorption studies were carried out on whole soils and soils selectively treated to remove IOs (IOR) and OM (OMR). The effects of $\mathrm{pH}$, time, and temperature were investigated. Results showed that PCP sorption was temperature and $\mathrm{pH}$ dependent; sorption decreased as both temperature and $\mathrm{pH}$ increased. Sorption was partly surface adsorption and partly partitioning within voids of IOs components as revealed by the kinetics models. The surface adsorption was multi-layer in nature. Equilibria were faster in the IOR soils than the untreated and OMR soils. IOs played greater roles in PCP sorption than OM. Removal of soil components, especially the IOs, as experienced in soils plagued by soil erosion, may lead to increased risks of PCP pollution of environmental media especially the aquifer.
\end{abstract}

(c) 2016 Elsevier B.V. All rights reserved.

\section{Introduction}

Contamination of surface and ground water resources and soils by pesticides are of growing environmental concern worldwide due to the potential risks associated with their persistence and toxicities to biota. Pentachlorophenol (PCP, $\mathrm{C}_{6} \mathrm{Cl}_{5} \mathrm{OH}$ ), a model environmental pollutant in this study, is one ionizable hydrophobic organic compounds (HOCs) usually employed as pesticides, herbicide, and antiseptic (Diagboya et al., 2014). It is a priority pollutant and a probable human carcinogen. Around locations where it has been used, high concentrations can be found in soils because of its slow biodegradation (He et al., 2006).

Soil is a dominant pesticides sink and also a potential reemission source. Sorption on soil is a critical process in the

\footnotetext{
t Capsule: This study showed that iron oxides may play a more dominant role than organic matter in sorption and fate of anionic pesticides in soil.

* Corresponding author.

E-mail address: pauldn2@yahoo.com (P.N. Diagboya).
}

control of pesticides because their fate depends both on their interactions with the soil's components, and the prevailing conditions of the soil and HOCs environment (Olu-Owolabi et al., 2014). This complexity makes it difficult to use a generalized sorption model for predicting retention and mobility. Hence, understanding pesticides sorption in soils is critical to predicting fate and transport, and ultimately their bioavailability in the environment.

Soil minerals (iron oxides (IOs), manganese oxides, and clays) and organic matter (OM) play varying roles in HOC retention and mobility (Diagboya et al., 2015; He et al., 2011). Speciation (distribution between labile, sequestered or unavailable, and bound forms in soils (Orecchio and Mannino, 2010)) of HOCs have been reported for whole soils and pure minerals, and these studies concluded that $\mathrm{OM}$ is the predominant sorbent unless the OM content is $<0.1 \%$ by mass (He et al., 2006; He et al., 2011; Iglesias et al., 2010; Kodesova et al., 2011; Orecchio and Mannino, 2010; Pu and Cutright, 2006; Smidova et al., 2012; Sun et al., 2010; Wang et al., 2008). However, even in the presence of higher OM contents, clay 
minerals have been implicated as the key sorbents for pesticides ( $\mathrm{Pu}$ and Cutright, 2006; Iglesias et al., 2010), but IOs are not specifically considered a major soil sorbent for pesticides due to lack of information on their specific contribution.

The quantitative analysis of soil components contribution to pesticides sorption is thus vital in understanding and predicting their fate, and such information can be incorporated into pesticides fate modeling. Current information is still insufficient in providing a complete understanding of the roles and mechanisms of soil components (especially the IOs) on pesticide sorption, as well as interconnected factors like ambient soil $\mathrm{pH}$ and temperature, pesticide contact time with soil, and soil cation exchange capacity (CEC), which may be vital in controlling the sorption process. This is important because direct extrapolation is generally impossible between OM content and pesticides bioavailability (Smidova et al., 2012; Pu and Cutright, 2006); thus, it may be incorrect to use soil OM (or carbon-normalized) sorption coefficients $\left(K_{\mathrm{OM}}, K_{\mathrm{OC}}\right)$ to predict pesticide mobility in soils. Therefore, the objective of this study is to evaluate the effects of soil organic matter and iron oxides components on sorption of PCP on soils and to predict the mechanism(s) of the sorption process.

\section{Materials and methods}

\subsection{Soil sampling, pretreatment and characterization}

Three sub-Saharan surface soils $(0-30 \mathrm{~cm})$ with contrasting physical and chemical properties were obtained from different agro-ecological zones (AEZs) of Nigeria (Table 1; SM Tables 1-2). The soil samples were pretreated by air-drying, gentle crushing, and sieving through a 230-mesh size sieve. The fine fractions were retained for IOs and OM treatments, physicochemical characterizations, and PCP sorption experiments.

The soils' $\mathrm{pH}$, particle size determination, $\mathrm{OM}, \mathrm{Fe}_{2} \mathrm{O}_{3}, \mathrm{Al}_{2} \mathrm{O}_{3}$, exchangeable and trace metals were determined following standard analytical methods (Diagboya et al., 2015). The cation exchange capacity (CEC) values were determined from the exchangeable bases and the exchange acidity. Exchangeable bases ( $\mathrm{Na}, \mathrm{K}, \mathrm{Ca}$ and $\mathrm{Mg}$ ) were determined by the $1.0 \mathrm{M}$ ammonium acetate $\left(\mathrm{NH}_{4} \mathrm{OAC}\right)$ method at $\mathrm{pH} 7.0$ while the exchange acidities were determined by titration method (Benton, 2001). The base saturation was the percentage of CEC contributed by the exchangeable bases. Metals in the soils were determined using inductively coupled plasma optical emission spectrometer (ICP-OES, Optima 5300DV) and ICP-mass spectrometer (ICP-MS, Agilent 7500). XRD crystallography was carried out with a Bruker phaser diffractometer system using the whole soil procedure (randomly oriented mounts).

\subsection{Removal of soil organic matter and iron oxides}

The soil samples were divided into three equal portions. Two of these portions were treated in isolation to remove OM and IOs using hot hydrogen peroxide $\left(30 \%\right.$ and $\left.80{ }^{\circ} \mathrm{C}\right)$ and sodium dithionite in citrate-bicarbonate buffer, respectively (McKeague, 1978). Significant (probably complete) removals of $\mathrm{OM}$ and $\mathrm{IO}$ in the samples were indicated by colour which turned reddish or brown and gray, respectively. The samples were washed several times to remove OM and IO from the soils, and these were labeled OMR and IOR, respectively.

\subsection{Sorption experiments}

Sorption experiments using whole and treated soils (OMR and IOR) were investigated by adding $10 \mathrm{~mL}$ of the PCP solution into brown vials containing $0.50 \mathrm{~g}$ of the soil sample. This soil mass to PCP solution ratio was carefully chosen to ensure that between 10 and $90 \%$ of the PCP in solution was removed. $40 \mathrm{mg} / \mathrm{L}$ working solutions ( $5 \% \mathrm{v} / \mathrm{v}$ ethanol/milipore ultra-pure water) containing $0.005 \mathrm{M} \mathrm{CaCl}_{2}$ and $0.01 \mathrm{M} \mathrm{NaN}$ as background electrolyte and biocide, respectively, were prepared from $500 \mathrm{mg} / \mathrm{L}$ stock PCP solution (prepared in 10\% v/v ethanol/milipore ultra-pure water), and used throughout the experiment except where otherwise stated.

The soil and PCP solution mixture were incubated for 1440 min (except for the effect of time), and the experiments were carried out at natural soil pH (Tables 1a and 2) except for the effect of $\mathrm{pH}$ where the $\mathrm{pH}$ was adjusted by using either 0.01 $\mathrm{M} \mathrm{HCl}$ or $0.01 \mathrm{M} \mathrm{NaOH}$. The effects of various operating variables (time: 5-1440 min; $\mathrm{pH}$ : 3-9; concentration: 20-40 mg/L; and temperature: 25 and $40^{\circ} \mathrm{C}$ ) on PCP sorption was investigated. During the experiments the vials were corked tightly with Teflon lined screw caps and wrapped with aluminum foil in order to minimize possible losses by photochemical decomposition; the vials were incubated in the dark while shaking at $100 \mathrm{rpm}$ in a temperature $\left(25^{\circ} \mathrm{C}\right)$ controlled shaker. The loss of PCP by photochemical decomposition, volatilization, and adsorption onto vial wall were compensated for by incubating blank vials containing PCP solution with no soil samples under the same conditions. At equilibrium, the vials were centrifuged at $4000 \mathrm{rpm}$ for $20 \mathrm{~min}$ and the concentrations of PCP in solution were determined using a Perkin-Elmer Lamda 950 high performance UV-vis-NIR spectrophotometer and $1 \mathrm{~cm}$ path length quartz cells. The peak at $320 \mathrm{~nm}$ was used to monitor the PCP sorption. All experiments were carried out in triplicate while the average of each experiment and standard deviation were used for the data analysis. Results showed that PCP losses were negligible.

\subsection{Data analysis}

The amounts of PCP sorbed on the soils were calculated using the Eq. (1):

$q_{e}=\frac{\left(C_{O}-C_{e}\right) V}{m}$

where $\left(C_{o}\right)$ and $\left(C_{e}\right)$ are the initial and final PCP concentrations in solutions, $q_{e}, V$ and $m$ are the amount of PCP sorbed $(\mu \mathrm{g} / \mathrm{g})$, volume $(\mathrm{mL})$ of PCP solution used, and mass $(\mathrm{g})$ of soil sample, respectively. Henceforth all PCP concentrations and amounts have been converted to ' $\mu$ ' rather than 'mg' to avoid working with very small size data.

The Lagergren (1898) pseudo-first order and pseudosecond order models, the Elovich, and the Weber and Morris (1963) intra-particle diffusion kinetics models (Eqs. (2)-(5)) were used to describe the sorption kinetics.

Pseudo-first order (PFO) $\log \left(q_{\mathrm{e}}-q_{\mathrm{t}}\right)=\log q_{\mathrm{e}}-\frac{k_{1}}{2.303} t$ 
Table 1a

Physico-chemical properties of the soil samples.

\begin{tabular}{|c|c|c|c|c|c|c|c|c|c|c|c|c|}
\hline \multirow[t]{2}{*}{ Soil } & \multirow[t]{2}{*}{$\mathrm{AEZ}^{\mathrm{a}}$} & \multirow[t]{2}{*}{ Sampling coordinate } & \multirow[t]{2}{*}{ pH water } & \multirow[t]{2}{*}{ pH $1 \mathrm{~N} \mathrm{KCl}$} & \multirow[t]{2}{*}{$\mathrm{OM}^{\mathrm{c}}(\%)$} & \multirow[t]{2}{*}{$\mathrm{CEC}^{\mathrm{d}}$} & \multirow[t]{2}{*}{$\mathrm{BS}^{\mathrm{e}}$} & \multicolumn{3}{|c|}{ Particle size analysis (\%) } & \multicolumn{2}{|c|}{ Oxides (wt\%) } \\
\hline & & & & & & & & Sand $^{f}$ & Silt $^{\mathrm{g}}$ & Clay $^{\mathrm{h}}$ & $\mathrm{Fe}_{2} \mathrm{O}_{3}$ & $\mathrm{Al}_{2} \mathrm{O}_{3}$ \\
\hline Lokoja (LF) & Southern Guinea SV ${ }^{b}$ & $6^{\circ} 45^{\prime} 00^{\prime \prime} \mathrm{E} ; 7^{\circ} 49^{\prime} 00^{\prime \prime} \mathrm{N}$ & 6.73 & 5.86 & 6.25 & 8.29 & 98.31 & 48.3 & 31.1 & 20.6 & 0.16 & 1.69 \\
\hline Gembu (GSF) & Montane & $11^{\circ} 15^{\prime} 00^{\prime \prime} \mathrm{E} ; 6^{\circ} 43^{\prime} 00^{\prime \prime} \mathrm{N}$ & 5.14 & 4.25 & 2.80 & 2.37 & 98.18 & 13.9 & 79.8 & 6.3 & 3.90 & 15.75 \\
\hline $\operatorname{Jos}(\mathrm{JB})$ & Northern Guinea SV ${ }^{\mathrm{b}}$ & $8^{\circ} 52^{\prime} 00^{\prime \prime} \mathrm{E} ; 9^{\circ} 48^{\prime} 00^{\prime \prime} \mathrm{N}$ & 5.17 & 4.08 & 3.57 & 2.98 & 85.25 & 42.3 & 57.1 & 0.6 & 3.13 & 9.12 \\
\hline
\end{tabular}

a AEZ - agroecological zone.

b SV - savanna.

c $\mathrm{OM}$ - organic matter

${ }^{d}$ CEC $\left(\mathrm{cmol} \mathrm{kg}^{-1}\right)$ - cation exchange capacity.

e BS - base saturation

f $\%$ sand $(>50 \mu \mathrm{m})$.

$\mathrm{g} \%$ silt $(2-50 \mu \mathrm{m})$.

h \% clay $(>2 \mu \mathrm{m})$.

Pseudo-second order(PSO) $\frac{t}{q_{\mathrm{t}}}=\frac{1}{k_{2} q_{\mathrm{e}}^{2}}+\frac{t}{q_{\mathrm{e}}}$

Elovich $\quad \mathrm{q}_{\mathrm{t}}=\frac{1}{\beta} \operatorname{In}(\alpha \beta)+\frac{1}{\beta} \operatorname{In}(\mathrm{t})$

Intra-particle diffusion(IPD) $q_{t}=k_{i}\left(t^{1 / 2}\right)+C$

where $q_{\mathrm{e}}$ and $q_{\mathrm{t}}$ are amount sorbed $(\mu \mathrm{g} / \mathrm{g})$ at equilibrium and at time $t$, respectively; and $k_{1}$ and $k_{2}$ are the rate constants of the PFO and PSO, respectively. $\alpha$ is the initial sorption rate

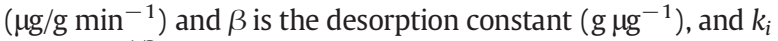
$\left(\mu \mathrm{g} / \mathrm{g} / \mathrm{min}^{1 / 2}\right)$ is the rate parameter of the intra-particle diffusion control stage.

The Langmuir (1916) and Freundlich (1906) adsorption isotherm models in their linear forms were used to describe the equilibrium data.

Langmuir $\frac{C_{e}}{q_{e}}=\frac{1}{Q_{o} b}+\frac{C_{e}}{Q_{o}}$

Freundlich $\log q_{e}=\log K_{f}+\frac{1}{n} \log C_{e}$

where $Q_{0}(\mu \mathrm{g} / \mathrm{g})$ is the soil maximum adsorption capacity; $b$ the binding energy constant; $K_{f}$ and $n$ are Freundlich isotherm constants; and other parameters are as stated above.

The thermodynamic parameters - standard free energy $\left(\Delta G^{\circ}\right)$, enthalpy change $\left(\Delta H^{\circ}\right)$, and entropy change $\left(\Delta S^{\circ}\right)$ were calculated using Eqs. (8) and (9) (Olu-Owolabi et al., 2014) (Supplementary material -SM 1).

$$
\log K_{C}=-\frac{\Delta H^{o}}{2.303 R T}+\frac{\Delta S^{0}}{2.303 R}
$$

$\Delta G^{0}=-R \operatorname{TIn} K_{c}$

\section{Results and discussion}

\subsection{Soil physicochemical properties}

The physicochemical properties (Table 1; SM Tables 1 and 2) were compared to those of reference soils of the moist lowlands in Nigeria (Fagbami and Shogunle, 1995). It was observed that the $\mathrm{pH}$ of the LF (Lokoja soil) was neutral while those of GSF (Gembu soil) and JB (Jos soil) were acidic. The content of $\mathrm{OM}$ values were regarded high and in the trend: LF $>$ JB $>$ GSF. Mineralogical analysis (Table 1b) showed that quartz was the most common mineral while kaolinite, hematite, and the carbonate minerals (aragonite, calcite, siderite, and dolomite) were common features of these soils. The 2:1 expansive clay minerals, montmorillonite and illite, were present in LF and JB. Soil minerals, trace elements and heavy metals (SM Tables 1 and 2) found on these soils were within the range observed in sub-Saharan soils (Diagboya et al., 2015; Fagbami and Shogunle, 1995; Olu-Owolabi et al., 2015).

In order to quantify the changes associated with the respective treatments, the organic matter, CEC and soil $\mathrm{pH}$ of untreated and treated soils were compared (Table 2; SM

Table 1b

The mineralogical composition of the soils determined from the XRD crystallography of soil samples.

\begin{tabular}{|c|c|c|c|c|c|c|c|c|c|c|c|}
\hline \multirow[t]{2}{*}{ Soil } & \multicolumn{10}{|c|}{ Mineral (\%) } & \multirow[b]{2}{*}{ Siderite } \\
\hline & Aragonite & Calcite & Dolomite & Gibbsite & Goethite & Hematite & Illite & Kaolinite & Montmorillonite & Quartz & \\
\hline $\mathrm{LF}$ & 11.77 & 0.29 & 16.21 & - & 18.26 & 1.51 & 15.41 & 11.52 & - & 25.03 & - \\
\hline GSF & 3.84 & 2.17 & 3.42 & 6.06 & - & 1.87 & - & 3.97 & - & 78.67 & - \\
\hline JB & 7.86 & 1.14 & 11.83 & 57.13 & - & 1.47 & 4.41 & 5.96 & 0.59 & 9.61 & - \\
\hline
\end{tabular}


Table 2

Comparison of selected physico-chemical characteristics of whole and treated soils.

\begin{tabular}{lllll}
\hline & $\mathrm{pH} \mathrm{H}_{2} \mathrm{O}$ & $\mathrm{pH} \mathrm{KCl}$ & $\mathrm{CEC}\left(\mathrm{cmol} \mathrm{kg}^{-1}\right)$ & \% organic matter \\
\hline LF & 6.73 & 5.86 & 8.29 & 6.25 \\
GSF & 5.14 & 4.25 & 2.37 & 2.80 \\
JB & 5.17 & 4.08 & 2.98 & 3.57 \\
LF OMR & 6.08 & 5.57 & 3.26 & 0.98 \\
GSF OMR & 4.38 & 3.98 & 2.14 & 0.83 \\
JB OMR & 4.14 & 3.63 & 3.87 & 0.92 \\
LF IOR & 7.79 & 7.01 & 17.9 & 4.31 \\
GSF IOR & 8.06 & 7.26 & 24.8 & 1.23 \\
JB IOR & 8.00 & 6.98 & 37.9 & 1.72 \\
\hline
\end{tabular}

Table 3). The low values of OM (Table 2) observed in the OMR soils might be attributed to the presence of ferrous ions in these soils (ferrous ions sometimes interferes with dichromateferrous sulphate titration) (McLeod, 1973), but the presence of OM in these soils may not be ruled out. It was also observed that removal of OM lowered the soils' $\mathrm{pH}$ and led to a reduction in the CEC values of LF OMR and GSF OMR soils; however, CEC of JB OMR increased significantly (29\%). The decrease in CEC of LF OMR and GSF OMR indicated that exchangeable cations of these soils are associated with the OM components; thus, removal of the OM led to reduction in CEC values. The increase in CEC for JB OMR may be attributed to a masking effect of OM on other soil components such as illite and iron oxides. Unmasking of these components by removal of OM exposed the exchangeable cations thus causing the increase. This result also showed that the CEC contribution from OM in JB soil was less significant than from other components. Removal of IO on the other hand resulted in general increase in $\mathrm{pH}$ and CEC $(>100 \%)$. This increase in CEC was attributed to the increases in exchangeable bases (notably $\mathrm{Na}^{+}$ions (SM Table 3 )) associated with soil components such as $\mathrm{OM}$, and the process may be similar to the unmasking effect (described above) on removal of IO. Perez-Novo et al. (2008) and Wang et al. (2008) have reported that similar soil treatments can result in changes in soil properties.

\subsection{Effect of $\mathrm{pH}$ on $\mathrm{PCP}$ sorption}

Results of the effect of pH (Fig. 1a; SM Fig. 1) showed that sorption was most favourable at low $\mathrm{pH}$ and dropped off in neutral and high $\mathrm{pH}$. The higher the OM content of the soil, the more the reduction in PCP sorption as pH increased; thus in Fig. 1a the depression for the LF curve (with higher OM) was more than those of GSF and JB. However, upon removal of OM, LF OMR (SM Fig. 1a) had the smallest depression. Similar results have been reported for soils and sediments (Li et al., 2009; Wang et al., 2008; Viraraghavan and Slough, 1999).

The PCP sorption trend on these soils was attributed to the surface chemistry of the soil components (the nature of the chemical charges available on the sorption sites of the soils at acidic, neutral, and basic pH regions), expansivity of the soil clay minerals, as well as the ionization state of the PCP molecules in solution at the prevailing soil solution $\mathrm{pH}$ (Lee et al., 1990; Li et al., 2009). At lower pH values: approximately 95\% of PCP species are protonated due to the high concentration of $\mathrm{H}^{+}$in solution, and are thus uncharged (low polarity) ( $\mathrm{Li}$ et al., 2009); OM (especially those containing phenolic and other aromatic groups) may shield off water by shrinking and becoming less polar; and the positive cations associated with soil components that contribute the bulk of the soil's CEC are uncharged due to stiff competitions from protons in solutions (Site, 2001; An et al., 2010). These conditions may result in increased hydrophobic interactions (such as the $\pi-\pi$ interactions) between (i) the aromatic components of $\mathrm{OM}$ and the uncharged PCP species, and (ii) the adsorbed PCP species on the soils surfaces and species in solution leading to multi-layer adsorption. These along with sorption of PCP species onto specific sorption sites on the soils, and partitioning within voids of expansive clays and OM might have resulted in the high PCP sorption at lower $\mathrm{pH}$.

At the neutral and higher $\mathrm{pH}$ values, the soil components characteristics are altered. For instance, approximately $95 \%$ of the PCP species in solution are charged or polar (Lee et al., 1990; Li et al., 2009); OM components may become charged or more polar (An et al., 2010), absorb water and swell; and the cations associated with the soil components become charged as well. These new conditions drastically reduce or eliminate $\pi-\pi$ interactions; and electrostatic interactions between the charged soil surface sites and the anionic PCP species become predominant as the major route of PCP removal from solution (Lee et al., 1990). Sorption of PCP species onto specific sorption sites and the partitioning within soil components are usually less affected by changes in the $\mathrm{pH}$ of the medium. Hence, the reduced PCP sorption observed was attributed to reductions in $\pi-\pi$ interactions as soil $\mathrm{pH}$ increased.

\subsection{Effect of time on PCP sorption}

In order to evaluate the rate of PCP sorption on these soils, the effect of time on PCP sorption was studied (Fig. 1b; SM Fig. 2). It was observed that equilibria for all three untreated soils were attained in $1080 \mathrm{~min}(18 \mathrm{~h})$. Fig. $1 \mathrm{~b}$ showed that the sorption was relatively fast in the first $180 \mathrm{~min}(3 \mathrm{~h}$ ) with $>70 \%$ of total sorption occurring within this time. After this, sorption was slow and characterized by almost equal sorption and desorption noticeable at equilibrium.

Comparing the PCP sorption rates on the untreated and treated soils (Fig. 1b; SM Fig. 2), it was observed that removal of OM from the soil did not affect the time for equilibrium attainment, while the IO removal reduced the time to $180 \mathrm{~min}$ $(3 \mathrm{~h})$. The unchanged equilibrium time for the OMR might be an indication that the surfaces and compartments involved in the sorption were almost intact upon OM removal, while in the IOR samples these sites or surfaces might have been distorted or removed resulting in fewer available sorption sites and faster equilibrium rate. This argument is in line with the amounts of PCP sorbed after the treatments which varied significantly depending on the contribution of the retained soil components to the sorption process (Fig. 2b; SM Fig. 2c and d). The results showed that though the OM contents of the LF was far greater than those of the GSF and JB ( $\geq 55$ and $42 \%$, respectively), the amount of PCP sorbed by GSF was almost $100 \%$ more than the LF while there was no significant difference in the amounts of PCP sorbed in the LF and JB soils. This observation was supported by results obtained with the OMR samples; the $q_{\mathrm{e}}$ $(\mu \mathrm{g} / \mathrm{g})$ values of OMR samples showed that OM in the OM-rich LF contributed $\leq 50 \%$ to PCP sorption while it contributed $\leq 5 \%$ in the lower-OM soils of GSF and JB (Fig. 1b; SM Fig. 2). However, 

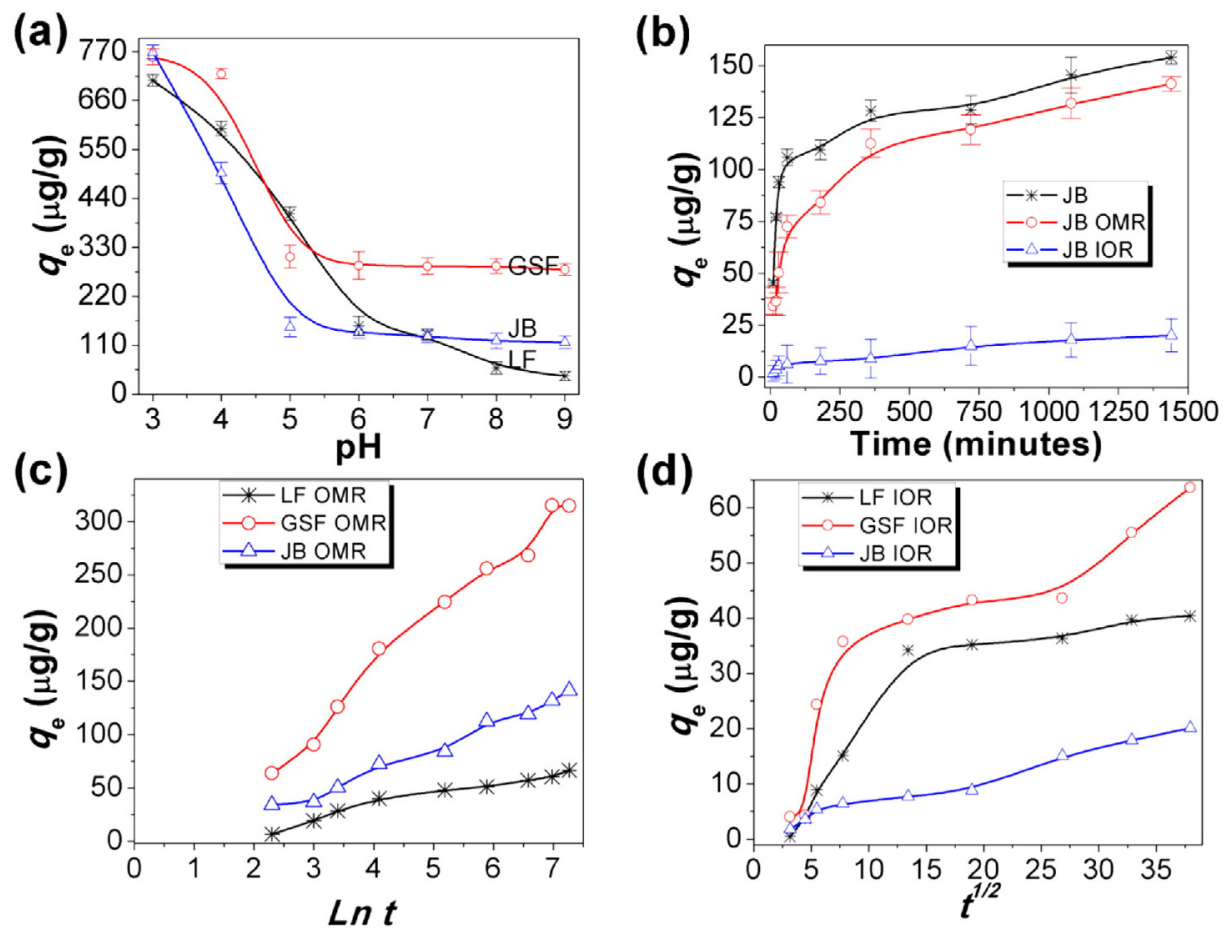

Fig. 1. (a) Effect of pH on PCP sorption on whole soils. (b) Effect of time on sorption on JB soil. (c) Elovich model plots for OMR soils. (d) Intra-particle diffusion model plots for IOR soils

in IOR samples the role of IO in the sorption became evident; there were significant reductions in PCP sorption in the IOR samples. For instance, by comparing the $q_{\mathrm{e}}(\mu \mathrm{g} / \mathrm{g})$ values of the whole soils and IOR samples, it was observed that the $q_{\mathrm{e}}$ reduced by $\approx 71 \%(100.7 \mu \mathrm{g} / \mathrm{g})$ in the LF IOR sample when compared with the LF (SM Fig. 2c), while the values were even higher $(\approx 85 \%)$ in the GSF IOR $(261.7 \mu \mathrm{g} / \mathrm{g})$ and JB IOR $(133.9 \mu \mathrm{g} / \mathrm{g})$ samples when compared to the GSF and JB soils, respectively (Fig. 2b;SM Fig. 2d). These results showed that IOs played greater roles than OM in the sorption of PCP on these soils.

These sorption trends upon removal of $\mathrm{OM}$ and $\mathrm{IO}$ components might also be attributed to the prevailing environmental conditions in the soils. PCP is a hydrophobic weak organic acid ( $\mathrm{pKa}=4.75$ ) and exists as the anionic or pentachlorophenolate species ( $\approx 95 \%$ ) at the $\mathrm{pH}$ of the studied soils (near neutrality) (Li et al., 2009). Since the bulk of PCP species in solution are the anionic form, electrostatic interactions between these species and the positively charged sorption sites mainly associated with the iron oxide components (which are also in the cationic form at the prevailing $\mathrm{pH}$ ) of the soils is likely to be the main adsorption method. Again as observed from this study, except the OM content of a soil is $>5 \%$, soil OM plays far less role than IO in PCP sorption.

\subsection{Sorption kinetics study}

The data generated from the effect of time were fitted to the PFO, PSO, Elovich and IPD kinetics models (Eqs. (2)-(5)) in order to understand the sorption mechanism(s). Comparing the PFO and PSO (Table 3) kinetics parameters (correlation coefficients $-r^{2}$ and the calculated sorption capacity $-q_{\mathrm{e}}$ ) values showed that the PCP sorption was better described by
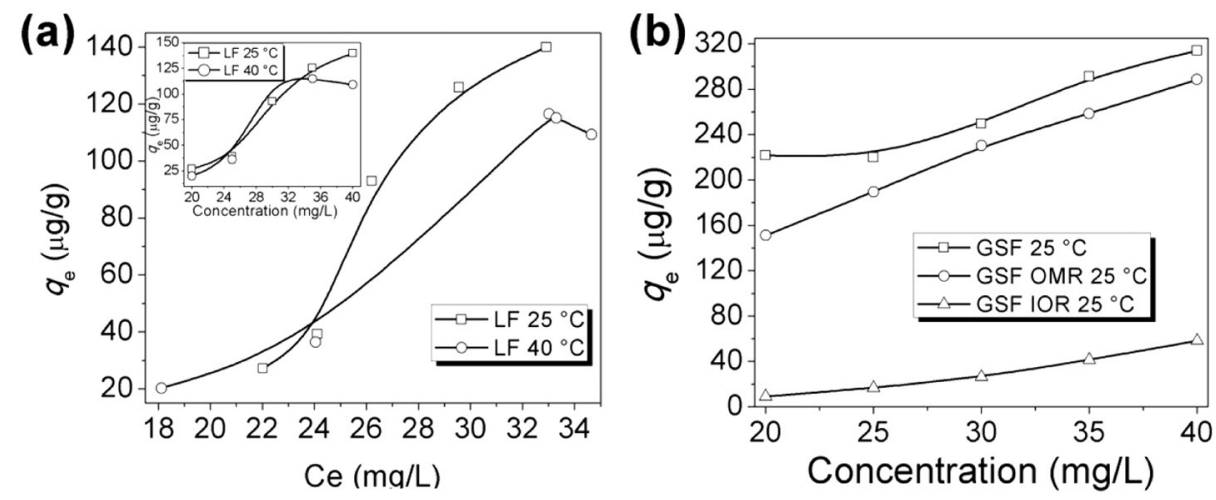

Fig. 2. (a) LF sorption isotherm curves (Insert: LF sorption trend as concentration increased) (b) Sorption trend on GSF whole and treated soils. 
Table 3

Kinetics model parameters for the whole, OMR and IOR soils.

\begin{tabular}{|c|c|c|c|c|c|c|c|c|c|c|}
\hline \multirow[t]{2}{*}{ Kinetics model } & \multirow[t]{2}{*}{ Model parameters } & \multicolumn{9}{|c|}{ Soil samples } \\
\hline & & $\mathrm{LF}$ & GSF & JB & LF OMR & GSF OMR & JB OMR & LF IOR & GSF IOR & JB IOR \\
\hline \multirow[t]{3}{*}{ PFO } & $q_{\mathrm{e}}(\mu \mathrm{g} / \mathrm{g})$ & 65.9 & 113.5 & 78.9 & 42.8 & 220.2 & 100.9 & 27.1 & 54.4 & 19.3 \\
\hline & $K_{1} \times 10^{-3}\left(\mathrm{~min}^{-1}\right)$ & 2.7 & 3.3 & 2.2 & 2.1 & 3.5 & 2.5 & 2.1 & 2.7 & 1.5 \\
\hline & $r^{2}$ & 0.754 & 0.918 & 0.917 & 0.917 & 0.921 & 0.948 & 0.864 & 0.808 & 0.982 \\
\hline \multirow[t]{3}{*}{ PSO } & $q_{\mathrm{e}}(\mu \mathrm{g} / \mathrm{g})$ & 166.7 & 333.3 & 166.7 & 71.4 & 333.3 & 142.9 & 52.6 & 66.7 & 21.3 \\
\hline & $K_{2} \times 10^{-5}\left(\mathrm{~g} \mu \mathrm{g}^{-1} \mathrm{~min}^{-1}\right)$ & 18.0 & 12.7 & 14.7 & 20.7 & 4.8 & 9.2 & 5.7 & 9.8 & 23.2 \\
\hline & $r^{2}$ & 0.998 & 0.999 & 0.994 & 0.994 & 0.995 & 0.994 & 0.736 & 0.959 & 0.931 \\
\hline \multirow[t]{3}{*}{ Elovich } & $q_{\mathrm{e}}(\mu \mathrm{g} / \mathrm{g})$ & 145.5 & 332.1 & 145.9 & 63.6 & 306.8 & 131.7 & 41.4 & 59.5 & 16.4 \\
\hline & $\beta\left(g_{\mu} g^{-1}\right)$ & 0.048 & 0.028 & 0.056 & 0.093 & 0.020 & 0.045 & 0.115 & 0.094 & 0.298 \\
\hline & $r^{2}$ & 0.953 & 0.77 & 0.925 & 0.956 & 0.983 & 0.980 & 0.950 & 0.901 & 0.897 \\
\hline \multirow[t]{2}{*}{ Intra-particle diffusion } & $C(\mu \mathrm{g} / \mathrm{g})$ & 58.5 & 187.5 & 70.2 & 18.7 & 91.6 & 36.3 & 5.0 & 11.3 & 1.4 \\
\hline & $K_{\text {id }}\left(\mu \mathrm{g} / \mathrm{g} / \mathrm{min}^{1 / 2}\right)$ & 2.70 & 4.35 & 2.36 & 1.39 & 6.73 & 3.02 & 1.12 & 1.41 & 0.49 \\
\hline \multirow[t]{2}{*}{ Experimental } & $r^{2}$ & 0.816 & 0.588 & 0.812 & 0.812 & 0.874 & 0.925 & 0.793 & 0.801 & 0.974 \\
\hline & $q_{\mathrm{e}}(\mu \mathrm{g} / \mathrm{g})$ & 147.1 & 330.6 & 147.8 & 64.3 & 312.8 & 135.6 & 41.8 & 57.7 & 17.5 \\
\hline
\end{tabular}

the PSO. The $r^{2}$ values of the PSO $(\geq 0.993)$ were closer to unity than those of the PFO (0.754-0.949) and calculated $q_{\mathrm{e}}$ values were also better correlated with the experimental $q_{\mathrm{e}}$ values. However, for the IOR samples both models parameters $\left(q_{\mathrm{e}}\right.$ and $r^{2}$ ) tend to describe the data appropriately. The fitting to the PSO can be ascribed to sharing or exchange of valence electrons between soil surfaces and PCP species (Olu-Owolabi et al., 2012).

The Elovich kinetics parameters $\left(q_{\mathrm{e}}\right.$ and $\left.r^{2}\right)$ values suggested that the sorption could be explained by this model (Table 3). Since the plots of $q_{\mathrm{t}}$ verses $\operatorname{In}(t)$ (Fig. 1c; SM Fig. 3 ) did not pass through the origin, this implied that there was some degree of boundary layer control between PCP species in solution and the soils' surface active sorption sites which was believed to be related to the rate controlling mechanism, and involves mainly electrostatic interactions between ionized PCP species and active surface sorption sites.

The IPD plots of $q_{t}$ verses $t^{1 / 2}$ were not linear (Table 3; Fig. 1d; SM Fig. 4), indicating that several mechanisms might be involved in the sorption. A linear plot is an indication that the sorption mechanism is majorly intra-particle diffusion, and if such a plot passes through the origin then intra-particle diffusion is the sole rate-limiting step. The multi-linear nature of the curves implied that both film diffusion (initial migration of PCP molecules towards the external surface of the soils) and intra-particle diffusion (movement of the molecules within the soil pores) were involved in the sorption. The magnitudes of IPD parameter $C(\mu \mathrm{g} / \mathrm{g})$, which indicates the thickness of the PCP molecules at the boundary layer, also supported this argument (Table 3 ). If the $C$ values were equal to the $q_{\mathrm{e}}$ values, that would have indicated that the PCP removal was solely surface adsorption; but since it was less than the $q_{\mathrm{e}}$, then the removal was partly surface adsorption and partly partitioning within soil components.

\subsection{Equilibrium PCP sorption, isotherms, and thermodynamics studies}

Equilibrium PCP sorption on the untreated and treated soils at different temperatures (Fig. 2a inserts; SM Fig. 5 inserts) showed that PCP sorption was concentration dependent, and increased with increase in concentrations. At higher temperature $\left(40{ }^{\circ} \mathrm{C}\right)$, a similar trend in PCP sorption was observed. This trend was attributed to the fact that at any particular concentration when the transport of HOCs, such as PCP, to the soil external surface film and internal pores are equal, the trans-boundary movement of PCP becomes insignificant, and increase in PCP concentration will lead to higher PCP removal due to multi-layer adsorption (Olu-Owolabi et al., 2014). Similar results have been reported on whole and individual soil minerals (Abdel Salam and Burk, 2009; He et al., 2006; Li et al., 2009; Olu-Owolabi et al., 2014).

It was also observed (Fig. 2a inserts; SM Fig. 5 inserts) that increasing the sorption media temperature from 25 to $40{ }^{\circ} \mathrm{C}$ caused a significant decrease in sorption on both untreated and treated soils. This showed that PCP sorption was exothermic and not favoured by high temperature. Olu-Owolabi et al. (2014) has stated that temperature affects low solubility organics by increasing the solubility and hence disorder in solution. This factor drives PCP species away from the soil's external surface film as well as out of the internal voids of clay minerals and OM; hence, the decrease in sorption. The decrease in sorption is also an indication of the strength of the interaction forces involved in PCP sorption on these soils; it implied that the forces involved in the sorption of PCP are mainly weak electrostatic and $\pi-\pi$ interactions, and VanWaal's forces requiring low sorption energies which are easily broken. Similar result has been observed by Abdel Salam and Burk (2009).

Equilibrium sorption results were similar to that of the effect of time in that IO contributed more to PCP sorption on these soils than OM (Figs. 1b and 2b; SM Fig. 2). Though sorption of PCP by soil IO and OM cannot be viewed in isolation because of the complex interactions between the various soil components (He et al., 2014), studies like this are beneficial in understanding the likely sorption trends for anionic organic compounds. The PCP sorption trend for the untreated soils is GSF $>$ JB $>$ LF, while for all soils, it is OMR $\geq$ untreated soil $>$ IOR (LF has a slightly different trend because of the higher OM content: untreated soil $>$ OMR $>$ IOR).

Isotherm curves obtained by plotting the $q_{\mathrm{e}}$ vs $C_{\mathrm{e}}$ data (Fig. 2a; SM Fig. 5) showed mainly the $S$ type isotherms curves at both temperatures, implying that the adsorbed PCP species were vertically oriented at the adsorption surfaces (Giles et al., 1960). S type isotherm curves exhibit 'co-operative adsorption' or a side-by-side association between PCP species; the more PCP species that is adsorbed, the easier it is for additional amounts to become fixed, and this was in agreement with the 
Table 4

The Langmuir and Freundlich models adsorption isotherm parameters for all soils.

\begin{tabular}{|c|c|c|c|c|c|c|c|}
\hline \multirow[t]{2}{*}{ Soil } & \multicolumn{3}{|c|}{ Langmuir sorption model } & \multicolumn{4}{|c|}{ Freundlich sorption model } \\
\hline & $\begin{array}{l}Q_{0} \\
(\mu \mathrm{g} / \mathrm{g})\end{array}$ & $\begin{array}{l}\beta \\
\left(\mu g \mathrm{~L}^{-1}\right)\end{array}$ & $r^{2}$ & $\begin{array}{l}q_{\mathrm{e}} \\
(\mu \mathrm{g} / \mathrm{g})\end{array}$ & $1 / n$ & $\begin{array}{l}K_{\mathrm{f}} \\
\left({\left.\mathrm{L} \mu \mathrm{g}^{-1}\right)}^{-1}\right.\end{array}$ & $r^{2}$ \\
\hline LF & 20.83 & 0.027 & 0.695 & 162.11 & 3.97 & 6456.5 & 0.876 \\
\hline $\mathrm{JB}$ & 1250.0 & 0.004 & 0.079 & 157.39 & 1.08 & 3.78 & 0.910 \\
\hline GSF & 555.6 & 0.051 & 0.872 & 302.15 & 0.50 & 62.37 & 0.916 \\
\hline LF OMR & 13.16 & 0.023 & 0.999 & 60.08 & 3.18 & 1548.8 & 0.979 \\
\hline GSF OMR & 735.3 & 0.011 & 0.405 & 299.49 & 1.31 & 4.30 & 0.935 \\
\hline JB OMR & 115.1 & 0.018 & 0.997 & 175.33 & 1.98 & 5.13 & 0.998 \\
\hline LF IOR & 0.71 & 0.027 & 0.771 & 39.24 & 6.98 & $2.8 \times 10^{9}$ & 0.965 \\
\hline GSF IOR & 7.64 & 0.025 & 0.912 & 59.59 & 3.87 & $1.9 \times 10^{4}$ & 0.998 \\
\hline JB IOR & 4.67 & 0.021 & 0.992 & 20.71 & 3.04 & 3258.4 & 0.991 \\
\hline
\end{tabular}

concentration dependence of PCP sorption noted earlier. This kind of association usually fits the Freundlich adsorption isotherm model.

Equilibrium sorption data for the soils at $25^{\circ} \mathrm{C}$ were fitted to the Langmuir and Freundlich models (Table 4). The model parameters showed that the data fitted the Freundlich model better than the Langmuir. The $r^{2}$ values of the Freundlich were closer to unity, and the calculated $q_{e}(\mu \mathrm{g} / \mathrm{g})$ values to actual experimental values (Table 3 ) than the Langmuir isotherm. Hence the Freundlich model which indicated sorption on heterogeneous surface sites of unequal energy as well as possible formation of PCP multi-layer on the sorption surface(s) at saturation was appropriate in describing these data than the Langmuir model which describes a rarely observed monolayer sorption on similar surface sorption sites of nearly equal energy. The small $n$ values of the Freundlich isotherms also indicated non-linear PCP sorption on predominantly heterogeneous sorption sites. JB OMR also showed good fitting to the Langmuir isotherm as well, and this may be an indication that the good fit to the Freundlich isotherm for this sample resulted from a combination of several Langmuir type adsorption isotherms which gave close approximation to the Freundlich type isotherm (Weber et al., 1992). These results implied that sorption of PCP on these soils occurred on heterogeneous surface sorption sites with possible multilayer adsorption of PCP species on the surface sorption sites of these soils, as well as partitioning within interstitial voids of the variable soil components.

Thermodynamic parameters $\left(\Delta G^{\circ}, \Delta H^{\circ}\right.$, and $\left.\Delta S^{\circ}\right)$ (Table 5) for untreated and treated soils showed that the sorption was

Table 5

Thermodynamic parameters for the whole and treated soils.

\begin{tabular}{|c|c|c|c|c|}
\hline \multirow[t]{2}{*}{ Soil } & \multirow{2}{*}{$\frac{\Delta H^{\circ}}{\left(\mathrm{kJ} \mathrm{mol}^{-1}\right)}$} & \multirow{2}{*}{$\frac{\Delta S_{-}^{\circ}}{\left(\mathrm{J} \mathrm{mol}^{-1} \mathrm{~K}^{-1}\right)}$} & \multicolumn{2}{|c|}{$\Delta G^{\circ}\left(\mathrm{kJ} \mathrm{mol}^{-1}\right)$} \\
\hline & & & $298 \mathrm{~K}$ & $313 \mathrm{~K}$ \\
\hline $\mathrm{LF}$ & 5.27 & 0.02 & -0.01 & -0.28 \\
\hline GSF & -70.37 & -0.21 & -8.66 & -5.55 \\
\hline $\mathrm{JB}$ & 374.00 & 1.27 & -3.52 & -22.52 \\
\hline LF OMR & 77.66 & 0.27 & -1.78 & -5.78 \\
\hline GSF OMR & -20.01 & -0.05 & -5.20 & -4.46 \\
\hline JB OMR & -14.06 & -0.04 & -2.49 & -1.90 \\
\hline LF IOR & 30.08 & 0.12 & -6.71 & -8.56 \\
\hline GSF IOR & 109.46 & 0.38 & -2.54 & -8.18 \\
\hline JB IOR & 67.47 & 0.24 & -4.56 & -8.19 \\
\hline
\end{tabular}

spontaneous and feasible (negative $\Delta G^{\circ}$ ); while the $\Delta S^{\circ}$ values showed decreased randomness as sorption proceeded to equilibrium. The $\Delta H^{\circ}$ values indicated endothermic sorption on soils having low (removed) IO content, but were exothermic for soils with high IO contents. The exothermic results confirmed the experimental observations that increase in temperature did not favour PCP sorption on these soils (Fig. 2 inserts; SM Fig. 5 inserts), while the endothermic results were attributed to the theoretical fact that energy input was needed to surpass the barrier for PCP sorption to occur. However, the energy also increased the solubility and mobility of PCP species in solution, hence the decreased PCP sorption observed.

\section{Conclusion}

The contributions and mechanisms of IOs and OM in PCP sorption on soils have been described. PCP sorption was temperature and $\mathrm{pH}$ dependent, reducing with increase in temperature and $\mathrm{pH}$. Iron oxides removal reduced equilibrium attainment time from $1080 \mathrm{~min}(18 \mathrm{~h})$ in the untreated and organic matter treated soils to $180 \mathrm{~min}$ ( $3 \mathrm{~h}$ ). Soil iron oxides played greater roles in PCP sorption than the organic matter content. Removal of IOs led to $\geq 85 \%$ reduction in PCP sorption, while removal of OM caused far less effect on soils with high OM (>5\%) contents (reduction by $\approx 40 \%$ ) but nearly no effect on soils with low OM $(<5 \%)$. Hence, loss of soil components, especially the iron oxides, as experienced in soil erosion, may lead to increased risks of PCP pollution of environmental media especially the aquifer.

\section{Acknowledgments}

We acknowledge the supports of the World Academy of Sciences (TWAS), Trieste Italy and the Chinese Academy of Sciences (CAS), China for the award of CAS-TWAS Postgraduate Fellowship (FR number: 3240255024) to P. N. Diagboya; the Chief S.L. Edu and Chevron research grant 2014; late Mrs. Rebecca A. Okoh and Mr. Victor P.O. Okoh, Department Estate Management, School of Environmental Sciences, Yaba College of Technology, Lagos Nigeria.

\section{Appendix A. Supplementary data}

SM 1: Data treatment; SM Tables 1-3. Further physicochemical properties of the soil samples; SM Fig. 1. Effect of $\mathrm{pH}$ on PCP sorptions; SM Fig. 2. Effect of time on PCP sorption and sorption trend on whole and treated soils; SM Fig. 3. Elovich model plots; SM Fig. 4. Intra-particle diffusion model plots; SM Fig. 5i-iii. Sorption isotherm curves (Inserts: Sorption trends as concentration increased). Supplementary data associated with this article can be found in the online version, at http://dx.doi. org/10.1016/j.jconhyd.2016.04.005.

\section{References}

Abdel Salam, M., Burk, R.C., 2009. Thermodynamics and kinetics studies of pentachlorophenol adsorption from aqueous solutions by multi-walled carbon nanotubes. Water Air Soil Pollut. 210, 101-111.

An, C., Huang, G., Yu, H., Wei, J., Chen, W., Li, G., 2010. Effect of short-chain organic acids and $\mathrm{pH}$ on the behaviors of pyrene in soil-water system. Chemosphere 81, 1423-1429. 
Benton Jr., J.J., 2001. Laboratory Guide for Conducting Soil Tests and Plant Analysis. CRC Press, New York.

Diagboya, P.N., Olu-Owolabi, B.I., Adebowale, K.O., 2014. Microscale scavenging of pentachlorophenol in water using amine and tripolyphosphate-grafted SBA-15 silica: batch and modeling studies. J. Environ. Manag. 146, 42-49.

Diagboya, P.N., Olu-Owolabi, B.I., Adebowale, K.O., 2015. Effects of aging, soi organic matter, and iron oxides on the relative retention of lead, cadmium, and copper on soils. Environ. Sci. Pollut. Res. 22, 10331-10339.

Fagbami, A.A., Shogunle, E.A.A., 1995. Nigeria: Reference soil of the moist lowlands near Ife (Oshun state). Soil Brief Nigeria 3. University of Ibadan, and International Soil Reference and Information Centre, Wageningen, p. 3.

Freundlich, H.M.F., 1906. Über die adsorption in lösungen. Z. Phys. Chem. 57A, 385-470.

Giles, C.H., MacEwan, T.H., Nakhwa, S.N., Smith, D., 1960. Studies in adsorption. Part XI. A system of classification of solution adsorption isotherms and its use in diagnosis of adsorption mechanisms and in measurement of specific surface areas of solids. J. Soc. Dye. Colour. 74, 3973-3993.

He, Y., Xu, J., Wang, H., Zhang, Q., Muhammad, A., 2006. Potential contributions of clay minerals and organic matter to pentachlorophenol retention in soils. Chemosphere 65, 497-505.

He, Y., Liu, Z., Zhang, J., Wang, H., Shi, J., Xu, J., 2011. Can assessing for potential contribution of soil organic and inorganic components for butachlor sorption be improved? J. Environ. Qual. 40, 1705-1713.

He, Y., Liu, Z., Su, P., Shen, X., Brookes, P.C., Xu, J., 2014. A new adsorption model to quantify the net contribution of minerals to butachlor sorption in natural soils with various degrees of organo-mineral aggregation. Geoderma 232, 309-316.

Iglesias, A., Lopez, R., Gondar, D., Antelo, J., Fiol, S., Arce, F., 2010. Adsorption of paraquat on goethite and humic acid-coated goethite. J. Hazard. Mater. 183 664-668.

Kodesova, R., Kocarek, M., Kodes, V., Drabek, O., Kozak, J., Hejtmankova, K., 2011. Pesticide adsorption in relation to soil properties and soil type distribution in regional scale. J. Hazard. Mater. 186, 540-550.

Lagergren, S., 1898. Zur theorie der sogenannten adsorption gelöster stoffe. K. Svenska Vetenskapsakad. Handl. 24, 1-39.

Langmuir, I., 1916. The constitution and fundamental properties of solids and liquids. J. Am. Chem. Soc. 38, 2221-2295.

Lee, L.S., Rao, P.S.C., Nkedi-Kizza, P., Delfino, J.J., 1990. Influence of solvent and sorbent characteristics on distribution of pentachlorophenol in octanolwater and soil-water systems. Environ. Sci. Technol. 24, 654-661.

Li, R., Wen, B., Zhang, S., Pei, Z., Shan, X., 2009. Influence of organic amendments on the sorption of pentachlorophenol on soils. J. Environ. Sci. 21, 474-480.
McKeague, J.A. (Ed.), 1978. Manual on Soil Sampling and Methods of Analysis, second ed. Can. Sot. Of Soil Sci. (Suite 907, 151 Slater St., Ottawa, Ont.).

McLeod, S., 1973. Studies on wet oxidation procedures for the determination of organic carbon in soils. CSIRO Division of Soils, Notes on Soil Techniques, pp. 73-79.

Olu-Owolabi, B.I., Diagboya, P.N., Ebaddan, W.C., 2012. Mechanism of $\mathrm{Pb}^{2+}$ removal from aqueous solution using a nonliving moss biomass. Chem. Eng. J. 195-196, 270-275.

Olu-Owolabi, B.I., Diagboya, P.N., Adebowale, K.O., 2014. Evaluation of pyrene sorption-desorption on tropical soils. J. Environ. Manag. 137, 1-9.

Olu-Owolabi, B.I., Diagboya, P.N., Adebowale, K.O., 2015. Sorption and desorption of Fluorene on five tropical soils from different climes. Geoderma 239-240, 179-185.

Orecchio, S., Mannino, M.R., 2010. Chemical speciation of polycyclic aromatic hydrocarbons in sediments: partitioning and extraction of humic substances. Mar. Pollut. Bull. 60, 1175-1181.

Perez-Novo, C., Pateiro-Moure, M., Osorio, F., Novoa-Munoz, J.C., Lopez-Periago, E., Arias-Estevez, M., 2008. Influence of organic matter removal on competitive and noncompetitive adsorption of copper and zinc in acid soils. J. Colloid Interface Sci. 322, 33-40.

$\mathrm{Pu}, \mathrm{X}$., Cutright, T.J., 2006. Sorption-desorption behavior of PCP on soil organic matter and clay minerals. Chemosphere 64, 972-983.

Site, A.D., 2001. Factors affecting sorption of organic compounds in natural sorbent/water systems and sorption coefficients for selected pollutants. A review. J. Phys. Chem. Ref. Data 30, 187-439.

Smidova, K., Hofman, J., Ite, A.E., Semple, K.T., 2012. Fate and bioavailability of (1)(4)C-pyrene and (1)(4)C-lindane in sterile natural and artificial soils and the influence of aging. Environ. Pollut. 171, 93-98.

Sun, K., Gao, B., Zhang, Z., Zhang, G., Liu, X., Zhao, Y., Xing, B., 2010. Sorption of endocrine disrupting chemicals by condensed organic matter in soils and sediments. Chemosphere 80, 709-715

Viraraghavan, T., Slough, K., 1999. Sorption of pentachlorophenol on peatbentonite mixtures. Chemosphere 39, 1487-1496.

Wang, X., Li, Y., Dong, D., 2008. Sorption of pentachlorophenol on surficial sediments: the roles of metal oxides and organic materials with co-existed copper present. Chemosphere 73, 1-6.

Weber, W.J., Morris, J.C., 1963. Kinetics of adsorption on carbon from solutions. J. Sanit. Eng. Div. Am. Soc. Civ. Eng. 89, 31-60.

Weber, W.J.J., McGinley, P.M., Katz, L.E., 1992. A distributed reactivity model for sorption by soils and sediments. 1. Conceptual basis and equilibrium assessments. Environ. Sci. Technol. 26, 1955-1962. 